CHROM. 6273

\title{
Acid degradation of flavonoids as an aid in their identification
}

In the course of previous studies of constituents from Larix needles ${ }^{1,2}$, small quantities of flavonol glycosides were hydrolysed according to standard procedures $\mathbf{s}^{3,4}$ in ethanolic or aqueous $\mathrm{HCl}$. In many cases, especially when very low concentrations were used, partial or complete degradation of the aglycone occurred, even when the time of hydrolysis was restricted to $5 \mathrm{~min}$.

Autoxidation of flavonols under acid conditions, leading to a benzoic acid, phloroglucinol (pliloroglucinol carboxylic acid) and carbon monoxide, has been described ${ }^{5-7}$. The rate of autoxidation in I $N \mathrm{HCl}$ at I00 $^{\circ}$ given, however, is much lower than that found in our experiments. This is probably due to the concentration used; higher concentrations of the flavonol glycosides produced under similar conditions a reasonable yield of the aglycone.

Knowing the effect of autoxidation, it may either be prevented by working under an inert atmosphere (nitrogen) or it may be used as a method of identification of the aglycone. In several cases, identification of the benzoic acid(s) obtained from acid degradation provided useful information on the purity and identity of the corresponding aglycone. The glycosides of isorhamnetin and syringetin, for example, proved difficult to separate ${ }^{2,8}$ and the aglycones differ only in their $R_{F}$ in phenol ${ }^{3}$. One of the compounds, isolated in low quantity from needles of Larix laricina, was identified as isorhamnetin-3-glucoside by chromatographic and spectral studies. Among the products of acid degradation, however, vanillic acid, as well as syringic acid was found, indicating the presence of a syringetin glycoside; this was later isolated and identified as syringetin-3-glucoside. Obviously, even in phenol, isorhamnetin and syringetin were kept at the same spot with $R_{F}$ similar to that of the reference isorhamnetin.

Acid degradation followed by identification of the benzoic acid residue(s) has now been introduced as a standard procedure in our laboratory. Chromatography on paper with benzene-acetic acid-water (I25:72:3) proved very useful in this connection, because this solvent system separates both the benzoic acids and the flavonols well, and at the same time indicates the number of hydroxyl groups $^{\mathbf{D}, 10}$.

Of course, a similar effect can be obtained by alkaline degradation. Acidic procedures, however, often provide information on the original aglycone, the benzoic acid produced and the sugar residues, and therefore seem much more suited for work on very small samples.

Botanical Laboratory,

G. J. NIEMANN

State University, Utrecht

(The Netherlands)

I G. J. NIEmann AND R. Berooy, Phytochemistyy, ro (I97I) 893.

2 G. J. NiEManN, Acta Bot. Neer., 2 I (I972) 549.

3 J. B. Harborne, Comparative Biochemistry of tho Flavonoids, Academic Press, London, Now York, r967.

4 T. J. MABRy, K. R. MARkinM AND M. B. Thomas, The Systematic Identification of Flavonoids, Springer Verlag, Berlin, Hoidelberg, New York, 1970. 
5 M. S. MAsRi, A. M. Booth AND F. DEEds, Arch. Biochem. Biophys., 85 (I959) 284.

6 C. G. Nordström, R. Finkalax and L. J. IEaruman, Suom. Femistil., B 36 (I963) Ioz.

7 C. G. Nordström and C. Majan1, Swom. Kemistil., B 38 (1965) 239.

8 J. B. Harborne, Phytochemistry, 4 (rg65) 647.

9 W. STECK AND S. H. WENDER, $J$. Chromalogr., Ig (I965) 564.

io E. Wong and A. O. TAYLor, J. Chromatogr., 9 (Ig6z) 449.

Received July I2th, I972

J. Chromatogr., 74 (1972) $155^{-1} 5^{6}$ 